\title{
The Contributions of Chilean Architects: Probing Local Value
}

\author{
MACARENA CORTES \\ Pontificia Universidad Católica de Chile
}

\author{
UMBERTO BONOMO \\ Pontificia Universidad Católica de Chile
}

\section{INTRODUCTION}

The International Conference of two thousand and sixteen: entitled "CROSS-AMERICAS: PROBING DISGLOBAL NETWORKS" has proposed to focus on the production of architectural knowledge. From the professional to academic, in the apparent substitution of globalization by an appreciation of local identities, towards a more customized, localized, and disglobalized future.

The Conference developed two central questions: What is driving these emerging post-comprehensive narratives? And how will the indeterminacy of these narratives inform design discourse and the broader practice of architecture? These questions aim to call the researchers to present their works, questioning the emergence of new narratives in architectural discipline.

\section{CHILEAN ARCHITECTURE}

During the last years, Chilean architecture has positioned itself internationally because of the quality as well as for the radicality of many of its works. Thus, although Chile is a small country south of the United States, the architecture has been disseminated in the specialized media and has been present in Biennials and other world cultural events. By having such a grand presence it has made this an unprecedented moment for national architecture. This auspicious context, still to be analyzed in its total dimension, requires reflective exercises that go further with the descriptions of works in catalogs.

Referring to the thematic provocation proposed by the Conference, the global versus the disglobal, it can be said that the experience of our guests is focused precisely on the valorization of the exceptional conditions of our locality, from geographical to cultural. Our country has an indomitable and varied nature that characterizes us and a creative culture that works at different scales and with different materials.

\section{OPENING KEYNOTE SPEAKER: ALEJANDRO ARAVENA}

In this context the first Keynote Speaker was Alejandro Aravena ${ }^{1}$. He is an architect, professor, urban designer, Pritzker laureate, and curator of the 15th Venice Biennale. The last two of these recognitions were granted to him in 2016. He was born in Santiago, Chile and graduated as an architect from Universidad Católica de Chile in 1992. In 1994, he established his own practice, Alejandro Aravena Architects.
His professional career is constantly moving between a practical dimension - developed under a very lucid pragmatism - and a theoretical dimension. Understanding theory, not so much as the will to theorize about things, but rather as the will to found the project in a logical and precise conceptual basis.

His discursive and communication skills, along with an extreme capability to synthesize problems - without reducing its complexities - have positioned Aravena as one of the worldwide leaders in contemporary architecture.

Alejandro considers professional practice as a collective work developed over the debate of ideas. That is why in 2001, he founded ELEMENTAL, which he shares leadership with his partners Gonzalo Arteaga, Juan Ignacio Cerda, Victor Oddó and Diego Torres.

ELEMENTAL is a "Do Tank" focusing on projects of public interest and with a social impact, which include social housing, public space, infrastructure, and transportation. From our point of view, one of the most important contributions of ELEMENTAL has not been the projects built in Chile, Mexico, China, Switzerland and the United States which have been awarded and recognized by all of us, but, the ability to demonstrate through these projects that architecture has distanced itself from some of the most important problems in society.

Once the projects have been built they can then be understood as an engine of transformation and change of urban and housing politics, an engine of change in society and, ultimately, an opportunity for people to live in better places.

\section{KEYNOTE PANEL: CAZÚ ZEGERS, TERES MOLLER AND MIRENE ELTON}

We can say that the monographic figures of Chile from magazines such as Casabella, Arquitectura Viva or A $+U$ used the extreme landscape of Chile as a way of interpreting the high architectural quality achieved in this distant country. Therefore, titles like Terra Neutra, Deep South or Ultima Chile proposed to describe the national architecture from this landscape and territorial sensibility, which would justify the unusual project responses. As a result of the economic rebound of the post-dictatorship nation and the rapid modernization it made Chile a place connected with development. This mixture of elements makes reference to the ability of the architecture to combine both the global and the disglobal. 
Nowadays, three architects will place their work in the contemporary field of the discipline. The Key note Speakers panel of the second day, led by three women spoke about the case of Cazú Zegers through the use of local materials and the references to the geographic ones. In the case of Teresa Moller through the work with the natural context and the local flora, and in the case of Mirene through the creativity of the project responses.

Cazú's ${ }^{2}$ firm outlines a different take towards Chilean architecture, in the search for an expressive architecture closely related to Chile, its territory, landscape and vernacular building traditions. The firm has a unique way of undertaking the design process, starting from the relationship between poetry and architecture which is based on a "light and precarious inhabitance" and understanding the greatest asset of Chile which is its territory. The project Tierra Patagonia Hotel is the most renowned example of this, a contemporary language based on the relationship between poetry and architecture, the project has been granted many awards including the Travel + Leisure Design Award for Best Design Hotel and Best Resort. Among many other awards and recognitions Cazú won the "Great Latin American Architecture Prize" and an Honorable Mention at the "ArcVision Prize" in Milan. She has given lectures all around the world including the MAXXI in Italy, Mundaneum in Colombia and Nicaragua, the GDS Harvard in Boston and the Millennium at the Polytechnic University of Milan.

Teresa Moller ${ }^{3}$ has been working in the field of Landscape Architecture for the past 30 years. She strongly believes in the power of simplicity. For her, a careful observation and awareness of the landscape is the key for developing social-culture projects and making nature more accessible to people. The most important aspect of her work is finding what is on the site and what is needed to make people experience nature. Teresa has always marveled how lucky she is to be able to work in the wide range of landscapes that exist in Chile. In her words the variable landscapes in Chile have taught her everything, as she has often met the extreme differences in environments from working in the desert of Northern Chile to the rain forests in Southern Chile.

Mirene Elton ${ }^{4}$ lives and works in Santiago de Chile, founding partner of Elton_Léniz office (since 1993), graduated from architecture at the Pontifical Catholic University of Chile (1996) and got a Masters in Science (Built Environment) at the University of London. Elton_Léniz office has developed their work with various partners including artists, architects and designers in order to characterize the office with great versatility being able to design on different scales. Among the projects in Chile and abroad are objects, furniture, exhibitions, commercial spaces, interior, housing, urban development, corporate projects and educational projects. Their work has been published in various media around the world and have been selected to participate in exhibitions such as the Biennale of Architecture of Santiago, Bienal of Saint Ettienne, The Furniture Fair in Paris and Milan, "Cut'n 'Paste" exhibition at the MOMA in New York, and recently in the Biennale di Venezia 2016. Among the awards and recognitions, they were awarded first price in the XI Bienal Panamericana of Quito, Ecuador (1998) , Chile - Diseño (2007) AOA Emerging Architects (2009).

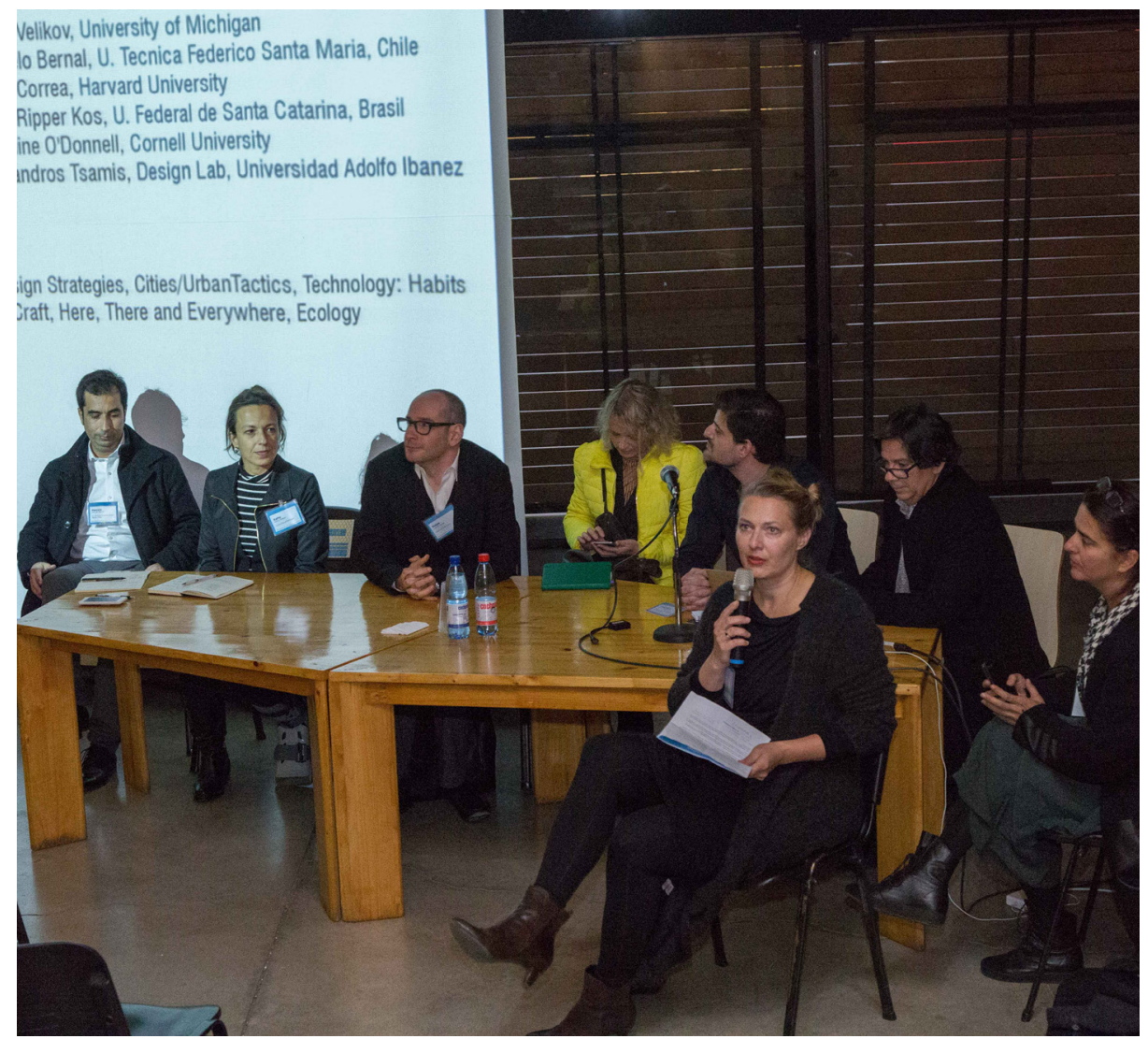

Figure: Panel discussion

\section{CLOSING KEYNOTE: PEZO VON ELLRICHSHAUSEN}

On the last day, Pezo von Ellrichshausen ${ }^{5}$ presented which is an art and architecture studio established in Concepcion, southern Chile, in 2002 by Mauricio Pezo and Sofia von Ellrichshausen.

They have been the curators of the Chilean Pavilion at the 2008 Venice Biennale and teach regularly in Chile in this Faculty and in the USA at the Illinois Institute of Technology. They have been visiting professors at The University of Texas and and Cornell University. Their work has been distinguished with the Mies Crown Hall Americas Emerge Prize, the Rice Design Alliance Prize, the $\mathrm{V}$ Iberoamerican Architecture Biennial Award and the XV Chilean Architecture Biennial Award.

They define themselves as an art and architecture studio. Many authors have written on the relationship between art and architecture, form Alberti to Boulle to Semper, however it was Vitruvio who lucidly (and probably firstly) exposes thus relationship: 
"The architect should be equipped with knowledge of many branches of study and varied kinds of learning, for it is by his judgement that all work done by the other arts is put to test. This knowledge is the child of practice and theory. Practice is the continuous and regular exercise of employment where manual work is done with any necessary material according to the design of a drawing. Theory, on the other hand, is the ability to demonstrate and explain the productions of dexterity on the principles of proportion"6.

It follows, therefore, that architects who have aimed at acquiring manual skill without scholarship have never been able to reach a position of authority to correspond to their pains, while those who relied only upon theories and scholarship were obviously hunting the shadow, not the substance".

The work of Sofia Ellrichshausen and Mauricio Pezo plays and synthetize this dual function of architecture. Their work are physical, built with materials, responding to life, light and space but they are also metaphysical as they evoke the sublime dimension of art.

On the other hand their drawings and paintings are theoretical explorations where symmetry is combined with colour in order to pose problems of their composition, order or volume, topics of universal character.

It is in the condition of universality of art, that the distinction between global or disglobal make crisis. And the fact that it is not so easy define which is the appropriate one to be applied to the production of this office is a proof of that.

\section{CONCLUSION}

The four offices of architecture, presented through their own architects during the ACSA 2016, allowed the public to observe the state of Chilean production in terms of local experiences. Although the main works were developed in Chile, they form part of the global architectural culture. The works give value to the specific conditions y determinant geography and climate such as the habitants, the materials, local constructive forms and many others. In this manner, the conferences dictated, contributed and deepened the discussion stated, where the value of the local can be understood from the disciplinary universality.

\section{ENDNOTES}

1. http://www.elementalchile.cl/en/about/

2. http://www.cazuzegers.cl/about

3. http://www.teresamoller.cl/estudio-del-paisaje/?lang=es

4. http://www.eltonleniz.cl/equipo/

5. http://pezo.cl/?m=1\&sm=1\&pn=info

6. Pollio, Vitruvius. "Vitruvius Pollio, The Ten Books on Architecture Morris Hicky Morgan, Ed."Vitruvius Pollio, The Ten Books on Architecture, BOOK I, CHAPTER I: THE EDUCATION OF THE ARCHITECT. Tufts University, n.d. Web. 8 Feb. 2017. <http://www.perseus.tufts.edu/ hopper/text?doc=Vitr.\%2B1.1\&lang=original $>$.

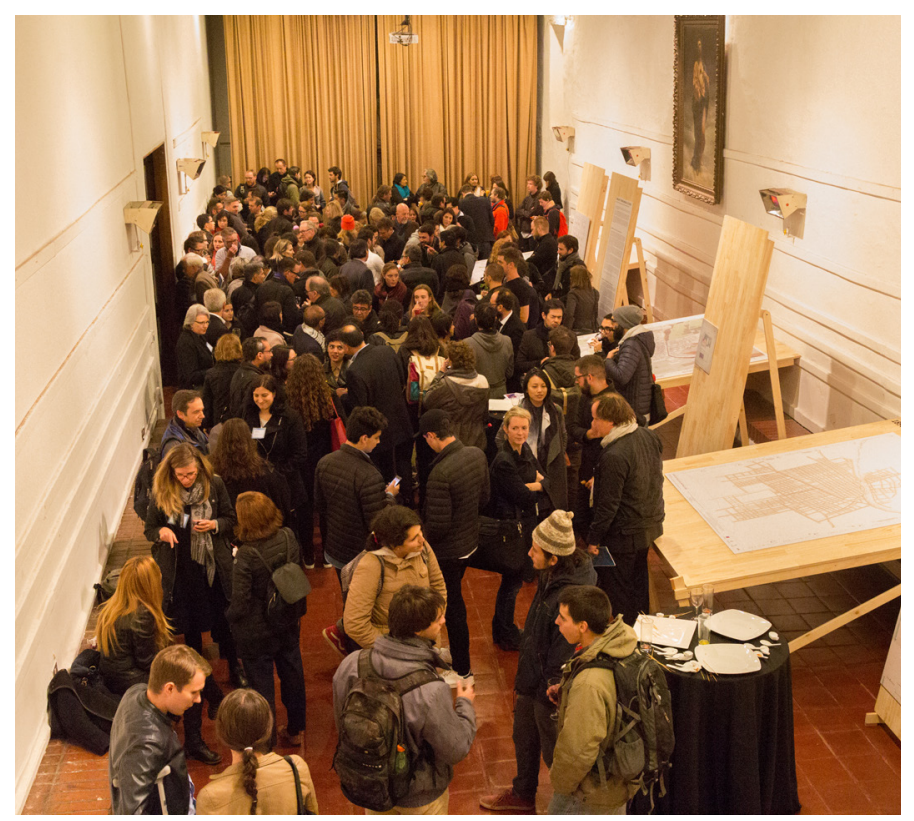

Figure: Opening reception at the Pontificia Universidad Católica de Chile, Escuela de Arquitectura 